\title{
Sustainable Development Planning: Examining the Mismatch of Urban Solid Waste Management Services in Bauchi Metropolis
}

\author{
Usman Haruna Abdu ${ }^{1}$; Mohammed Danladi²; Badara, B. Bakoji ${ }^{3}$; Yakubu Mohammed Nma ${ }^{4}$ Kawuwa. A. \\ Sarkile ${ }^{*}$ \\ Department of Architecture, Faculty of Environmental Technology, Abubakar Tafawa Balewa University, \\ P.M.B 0248, Bauchi, Nigeria \\ Email: abusarkile@gmail.com Phone: +2348036370030, (CORRESPONDING AUTHOR)
}

\begin{abstract}
Municipal solid waste systems are essential components of environmental infrastructure in human settlements. This system comprises all the activities undertaken from the point of waste generation to the final phase of disposal. It is an important environmental health service and an integral part of basic urban services. In most cities of developing world, waste service provision is a responsibility of municipal authorities. However, solid waste generation out-weighed the collection capacities of these municipalities and agencies responsible for waste collection and its management. The problem of solid waste generation and management is also compounded, and increasingly becoming difficult for these agencies due to lack of availability of reliable data on existing waste streams within the metropolis. This study compared the solid waste management service provided by Bauchi State Environmental Protection Agency (BASEPA) and the result of a study on waste characteristics and management streams in Bauchi Metropolis. The methodology of the study used waste characterization, physical interviews, focus group discussion and observations; the results finally established the lacuna between the current situation and the unsustainable waste management services rendered by the municipality which became a bottleneck in achieving a sustainable urban solid waste management services in Bauchi metropolis respectively..
\end{abstract}

Keywords; Solid Waste, Solid Waste Management, Urban Areas, Environmental Agencies, Bauchi Metropolis

DOI: $10.7176 / \mathrm{CER} / 12-3-06$

Publication date:March $31^{\text {st }} 2020$

\subsection{INTRODUCTION}

Municipal Solid Waste is defined to include refuse from households, non-hazardous solid waste from industrial, commercial and institutional establishments, market waste, yard waste and street sweepings (Schubeler et al., 1996). Municipal solid waste management (MSWM) refers to the collection, transfer, treatment, recycling, resource recovery and disposal of solid waste in urban areas). Solid waste management is an important facet of sustainable development for any country and global initiatives greatly support the prioritizing of SWM. (Ndum 2013, Usman 2017). Residential households are mainly the major stakeholders interested in receiving effective and dependable waste collection service at a reasonably low price. In most urban centers of developing countries, residential areas, mostly the low income residential areas, solid waste service are unsatisfactory. Increased in generation and disposal of municipal solid waste became an increasing problems in urban areas due to high population density, urbanization and industrialization. (Saifullah, 2015; Patel and Baredar 2016; Thaiyalnayak 2016); consequently, pressure to improve solid waste collection service arises as other service became available and awareness mounts regarding the environmental and health impacts of poor waste collection service. However, despite the increasing rate of waste generation, collection facilities are declining due to population growth and finances (Abdelgawa, 2015). And households are the major contributors of municipal solid waste. (Maskey and Singh, 2017). Okot-Okumu (2012) reported that about $80 \%$ of the solid waste generated in capital cities of Africa came from domestic sources. Increased generation of household waste, which surpasses the assimilation capacity of the ecosystem and the insufficient installed capacity of disposed yards for its handling, promotes the proliferation of open air dumps, with an increased threat to the public health, ecosystem, and quality of life. (Karak, Bhagat, and Bhattacharyya, 2011).

In cities of the developing world, municipalities are mostly responsible for the solid waste management at city level (Muggaga, 2006 \& Cointreau, 1994). However, most municipal authorities in developing countries have failed to provide their expanding populations with adequate services for managing solid waste as well as for providing water and sanitation (Abdul, 2007, in Solomon, 2011). Akinsulire (2005), in Usman, 2017, observed 
that recent events in major cities of African countries have shown that the problems of waste management has became a monster that has thwarted most efforts by international, federal and states governments as well as city authorities and professional alike. Also (Bovea et al., 2010 \& Zurbrugg et al., 2012) in Cherian \& Jacob (2012), highlighted that waste management is a complex process that requires a lot of information from various sources such as factors on waste generation and waste quantity forecast.

Various actors or stakeholders participates in every solid waste management system in both the developed the developing countries. In principle, these actors are part of every solid waste management; the municipal government NGOs/CBOs, households or service users, private formal/informal sectors and donor agencies. (Muller \& Hoffman, 2001, in Usman, 2017). However, in most Nigerian urban centers, municipal solid waste management is characterized by inadequate collection and improper disposal, due to the inability of the municipalities to handle the increasing quantities of solid waste generated. The uncollected waste littered the streets, roads and public drains and this is an obvious cause of degradation of the environment in most cities in Nigeria. But solid waste management (SWM) is one of the most visible urban services whose effectiveness and sustainability serves as an indicator for good local governance, sound municipal management and successful reforms (Okot-okumu, 2012). Households' solid waste generation and management are generally unknown to government officials especially the responsible agencies. Therefore one of the challenges facing the leaders and governments in stream lining waste management services is the increase quantities and diverse characteristic of waste generated by their residents.

\subsection{MATERIALS AND METHODS}

\subsection{Study Area}

Bauchi metropolis serve as the headquarters of Bauchi state and is located between latitude 9" 00' and 9" 30' North of the equator and longitude 10" 25 and 11" 20 ' east of the Greenwich meridian. It occupies a total land area of 3,604.0 hectares. It is about $128 \mathrm{~km}$ north-east of Jos and $150 \mathrm{~km}$ west of Gombe town. Bauchi is one of the major towns in northern Nigeria within Sudan savannah vegetation zone. There are two main seasons experienced in Bauchi town, the cold dry season and hot wet season. The cold dry season last from October to April and the wet season is from May to September. For most time of the year, the town is apparently hot. The hottest months are April and May on the average with highest temperature record of 40-50 $\mathrm{C}$ while the coldest month are December and January (Harmattan) with a minimum temperature record of $6.11^{\circ} \mathrm{C}$ and $7.22^{\circ} \mathrm{C}$ respectively.

Information was obtained from officials of Bauchi State Environmental Protection Agency (BASEPA), Bauchi State Commission for Women and Youth Development and Rehabilitation (BACYWORD) and the household level. Other government agencies like the National Population Commission (NPC) and Federal Office of Statistics were interviewed to obtained demographic data. The sources of data collected and used in the study were obtained from a total 33,339 households of Bauchi metropolis. The households were purposely selected from 8 Districts, 13 Wards and 14 Sub-wards of the metropolis. In this research, the sampling frame of 33,339 would be represented by 378 households, purposely selected from the study area.

Qualitative methods used in this study include: reconnaissance survey, semi-structured interviews and, direct observations. Quantitative method used was the household survey questionnaire and waste characterization study. Descriptive statistics such as means, frequencies, standard deviation were used to analyze the qualitative data obtained from questionnaire survey.

\subsection{RESULTS AND DISCUSSION}

\subsection{Bauchi State Environmental Protection Agency (BASEPA)}

Bauchi state environmental protection agency was established by edict N0. 3 of 1997 and came into force on $10^{\text {th }}$ June 1997 to replace and take over the activities of the defunct TASK FORCE on environmental sanitation which was abrogated in 1996 to;

a) Implement environment policies towards protection sustenance and development of the environment generally

b) Identify, detect and involve any environmental problem such as pollution of all kinds

c) Represent the state in any matters pertaining to plans, producers, or negotiation for governmental arrangement relating to environment 
d) Arrange and coordinate planning for the urban and regional process in the state and or liaise with private or public institution that engages in environmental activities.

e) Direct and control the collection and disposal of refuse in the whole state (Bogoro, 2012)

The operations of BASEPA include;

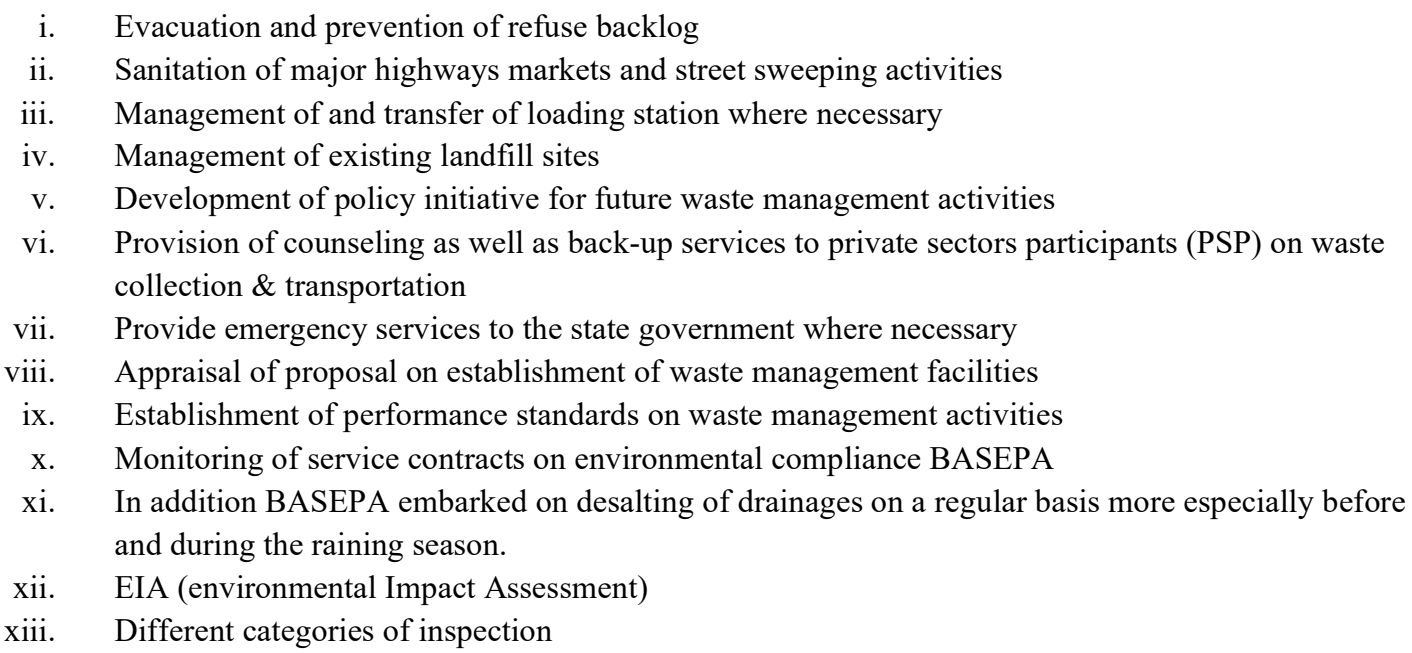

Table 1: Available Equipment in BASEPA

\begin{tabular}{lllll}
\hline S/N & Type of equipment & No. functional & No grounded & Total \\
\hline Pay loader & 1 & 1 & 2 \\
Open tipper $\left(6.5 \mathrm{~m}^{3}\right)$ & 5 & 5 & 10 \\
Tractors (open body) & 2 & 3 & 5 \\
Compactor trucks & 2 & 2 & 4 \\
Roro (wheel-containers) & 20 & - & 20 \\
\hline
\end{tabular}

Source: BASEPA, (2015)

\subsection{Waste Management Strategy in Bauchi Metropolis by the Municipal Authorities -Bauchi State Environmental Agency (BASEPA)}

According to BASEPA (2013), about 492,750 metric tonnes of waste is generated annually in Bauchi and its environment. There is, therefore the need for the authorities to improve their strategies for managing domestic solid waste both in the technological and managerial dimensions. Over the years, Bauchi metropolis, the capital of Bauchi state, north-east Nigeria, has witnessed various approaches to solid wastes management, but the problems has been one; inefficient solid waste management system. Recent population growth and uneven urbanization patterns in Bauchi compounded the problems. These coupled with lack of strategies, technical and institutional inefficiencies and effectiveness continue to worsen the situation. Some of the solid waste management option that have been carried out in the past without success to solve the problem of refuse disposal in Bauchi metropolis include monthly environmental sanitation programme, operation keep Bauchi clean and street cleaning exercises and mobile courts on environmental sanitation. Notable efforts by the state government dates back to the late 1990s, the era of new democratic dispensation in Nigeria to 2006. This operation facilitates the total evacuation of heaps of refuse dumps (Bingi) within the old-walled city of Bauchi by the state agency (BASEPA). These piles 
of refuse are either left on burrow pits, or as left-over spaces within the old-city, and were found in most part of the residential areas in the town.

Notable ones are the;

i. Malashe at Wunti converted to a Juma'at Mosque

ii. Jakara around Ilelah-Central Market, converted to shopping complex and a Bank building

iii. Bingin Galadima, now a residential area

iv. Bingin Sarki at Tura, now a primary school building

v. Bingin Kwara at Wunti, now a residential area.

vi. Ganjuwa at Jahun/Ganjuwa, now residential area.

However, following the evacuation of these wastes dumps owners of the plots reclaimed (usually through inheritance) and developed their plots. As an alternative to these dumps sites, the government provides masonry bins and wheel container (Roro) in some locations within the metropolis. These facilities were grossly inadequate and received low frequency of evacuation by the state agency. These resulted to unhealthy attitudes of illicit and indiscriminate disposal of refuse in public drains, public spaces, uncompleted building sites, vacant plots and so on. During raining days, these wastes were washed away and blocked drains causing flooding and contamination of well waters in the affected wards and districts.

\subsection{Second Strategy (Waste Management at State Level)}

In 1997, the Bauchi state environmental protection agency, designed a strategy for municipal solid waste management in the major urban centers in the 3 senatorial districts of Bauchi state. The process involves collection and transportation of waste from the communal storage facility to final disposal site (open dumping). In Bauchi metropolis, the process involves the dumping of refuse by the households, commercial facilities and schools and so on into the designated dumping site (DDS), the agency (BASEPA) workers collect the waste manually from the DDS using shovels and wheel-barrows and transport them to the transfer stations. The municipal agency is responsible for collection of the waste from the DSS to transfer station and final processing site, using pay loaders, compactors trucks and tippers. About 500 DDS, and 20 transfer stations were proposed or constructed (BASEPA, 1997). The final dumping sites in the metropolis;
a. Burrow pit-on Bauchi-Tafawa Balewa road after Birshi village
b. Open dump along Bauchi-Jos road
c. Burrow-pit along Bauchi-Gombe road at Dungulbi village

All these areas are now surrounded by settlements which stand the risks of exposure to methane and leachate and other harmful effects from the dump sites. However, the strategy could not be implemented successfully nor survive time due to the following; Urbanization/environmental factors; the fast growing nature of the metropolis in terms of population, housing density and land use made the entire process almost impossible. Indiscriminate dumping of waste became the practice of the day. Most of the DDS were demolished by residence due to low collection by the agency, or because of their proximity to the residential areas. The transfer station, or communal dumping sites were:

i) Reclaimed by the inhabitants of the areas. Inadequate and narrow access to collection sites prevents regular and proper collection. (Shubeler, Wehrle, Christen, 1996) highlighted that at the level of the built environment, the size and structure of a settlement has an important influence on the character and urgency of waste management

ii) Application of inappropriate technology in collection, transportation and disposal of waste contributed to the failure of the strategy. The use of compactor trucks in collection and disposal of waste that is highly organic reduced the efficiency of the system. Waste continues to accumulate in the various districts of the metropolis due to lack of appropriate equipment and machines.

iii) Low participation of the major stakeholders (households) contributes immensely to the failure of the system. The system is not inclusive with all the important stakeholders. There is no perceived need of either the communities or householders in the waste management system. The attitude of waste generators towards waste management has not been given consideration in execution of the program or in key decision making. As the process is capital intensive, other factors such as finance, incorrect balance between labour, equipment and low coverage of services makes the system not feasible. 


\subsection{Third Strategy}

\subsection{1 (The Use of Public Private Partnership (PPP) in Municipal Solid Waste Management)}

Between the years, 2007 to 2013, the state government admits the incapacitation of the state agency in adequate waste management. As a result it entered into Public Private Partnership (PPP) with Cosmopolitan cleaners and National Union of Road Transport Workers (NURTW) -Tipper Branch, Bauchi. The two partners in collaboration with the Bauchi State Environmental Protection Agency (BASEPA) and Bauchi State Commission for Youth and Women Rehabilitation and Development (BACYWORD) embarked on street sweepings and daily waste collection on some major streets, and fortnightly and monthly in other parts of the metropolis. The process required households and other commercial outfits to dumps or deposit their wastes daily at undesignated points along the streets for collection, with no supervision monitoring or involvement of households, or wards heads in the process. However, the collection became sporadic, irregular and sometimes absent in some cases. Consequent upon these, the unattended and accumulated wastes encouraged scavengers, domestic animals and birds patronizing these waste dumps, spreading it on the streets. Also residents who received low collection in their areas disposed their wastes at night on vacant plots and public drains.

In the case of solid waste management, the ultimate aim of PPP is to provide effective SWM to residents in terms of amount of waste collected, and the sustainability of the service provisioning. In this context of the role of BASEPA in assisting stakeholders in this study, two cases of PPP can be noted. The first case is the PPP between BASEPA (State Government) and private waste contractors (Cosmopolitan Cleaners and NURTW - Tipper Branch, Bauchi). The second case of the PPP is between the formal waste contractors and the household (mostly in medium and low density sub-wards). The first case of PPP is governed mainly by a legal contract that defines the partners involved. The legal contract is the pillar of the municipality to monitor the performance of the waste contractors. The second case of PPP emerged as a result of the under servicing of the affected households by the Municipal agency. The householders in their quest for effective waste collection services engaged the waste contractors for a negotiable amount which is paid monthly for their waste evacuation.

Towards the end of year 2013, the major (PPP) partners' Cosmopolitan Cleaners were disengaged from the service (BASEPA, 2014). This left the state agency (BASEPA) in critical situation with no designated point of refuse collection and disposal, and few vehicle and trucks to collect the ever-increasing waste generated in the metropolis. However, monthly environmental sanitation exercise has been in placed with mobile court for prosecuting defaulters. Unfortunately, this has not made significant impact as it has not received the support of the households and the communities. As an alternative measure, the state agency also proposed to the state government the purchase of some locations (houses and commercial blocks) to convert them to waste collection and disposal points. The solution seems not cost effective for the government and may not yield positive result.

In 2015, the change of administration in the state saw the revival of the PPP. Till today, waste management in Bauchi metropolis is still the status quo of the previous strategies. Cosmopolitan cleaners as the major PPP partners, saddled with the responsibility of waste collection and the state agency undertakes the street cleaning exercises.

From the foregoing, it can be seen in all the attempted measures, negligence on the part of the government to involve the household as major producers of solid waste, handlers of waste at the primary phase of solid waste management and recipients of waste management services contributes to the failures of successful solid waste management in Bauchi. Stressing the complex nature of municipal solid waste management (MSWM), the UNDP/UNCHS (Habitat) 1996, identified Municipal Solid Waste Management (MSWM) as a complex task which depends as much upon organization and cooperation between households, communities, private enterprises and municipal authorities, as it does upon the selection and application of appropriate technical solution for waste collection, transfer, recycling and disposal.

\subsection{Waste Management Strategies by the Households}

\subsubsection{Solid Waste Generation in Bauchi Metropolis}

This study found that per capita waste generation in the selected sample varies from $0.22 \mathrm{~kg} / \mathrm{capita} /$ day to about $0.48 \mathrm{~kg} / \mathrm{capita} /$ day, obtained at the sub-ward of Kofar Wambai and Federal Low-cost respectively. While 0.30 $\mathrm{kg} / \mathrm{capita} /$ day was obtained for Bauchi. The implication is that about 126.5 metric tonnes of household solid waste is generated in the studied sub-wards in Bauchi metropolis daily which need to be disposed safely in a controlled manner that may not be harmful to the environment. An important factor that this study observed to have affected the value of per capita solid waste generation which many studies neglected is the architecture and planning 
influences of the study area. According to the UN-HABITAT (2011), the failure to consider parameters of each particular location has led to many failed systems and wastages of huge sum of money in solid waste management in developing countries. Due to the abundance spaces enjoyed by the households in the sub-wards of old GRA and new GRA west (metropolitan transition area), within and outside their compounds and premises, residence tend to burnt their yard trimmings, garden waste together with waste collected from their sweepings. About $50 \%$ of the studied households in these areas who were observed to receive low frequency of collection burnt their waste before collection

\subsubsection{The Composition of Domestic Waste in Bauchi Metropolis}

For the purpose of this study, household solid waste is defined to comprised waste generated by the domestic activities and non-domestic activities discarded by the householders in the households. The waste characterization study provided useful data on the physical composition of household waste in the studied sub-wards. Eight major components of the household waste have been presented with their relative percentages. These components are Garbage (organic/kitchen waste) $61 \%$, Residues (sweepings/ash) $14 \%$, Polythene $13 \%$, Plastics $2.8 \%$, Metal/Aluminum $0.9 \%$, Glass $1.9 \%$, Paper $4.2 \%$ and Textiles $2.2 \%$. In Bauchi metropolis, domestic wastes constitute $61 \%$ organic (biodegradable, kitchen waste). This is typical of most wastes from cities of the developing countries. The percentage of organic component is usually higher. This fraction was observed to be as a result of household's consumption of much unprocessed food, despite the different lifestyles of the residents in high, medium and low income areas. This may be as a result of the availability of fresh food items in the study area which made it affordable to most categories for families. The information obtained from the results of this study is vital in planning solid waste management at household level. It helps in identifying material categories and their relative proportions in the household waste stream for; potential source recovery reduction composting possibilities, and recycling. Also, full knowledge of the constituents and composition of the waste stream provides information which is essential in selection of the type of container most appropriate for storage and transport, choice of a suitable disposal method and determination of the environmental impacts of the waste if improperly managed.

\subsubsection{Waste Storage at the Studied Sub-Wards}

The type of waste storage containers is significant in waste management at it changes waste generation and variation in waste composition. This study found that $93 \%$ of the respondents have various types of waste storage containers. $42 \%$ uses metallic containers mostly in form of old metal containers, $48 \%$ uses plastics buckets usually old empty point bucket of 25 liters capacity, $5 \%$ uses polythene bags and $5 \%$ uses other containers as empty boxes and cartons which are eventually dispose off together with the waste. However, the municipal agency (BASEPA) required that each household should use a container which non-rust, plastics, alloy or galvanized. The households might not be aware or are not ready to adhere to these recommendations and instead used containers that suit their choices and environment. According to (Solomon, 2011) a good bylaw might exist in waste management, but if not applicable to the situation on the ground becomes irrelevant and would not guarantee the proper waste management practices by the households.

The implication of these findings indicates that social prerequisite is relevant when it comes to improve household solid waste management. Observations in this study reveals that in all the studied sub-wards solid waste storage containers are kept in the yards outside the sleeping areas. According to Solomon (2011), these practices have a cultural background for most Africans as it is unacceptable to store waste inside the house where people sleep.

\subsubsection{Movement of Waste Generated From the Households to Communal Bins}

These refers to the moving of the waste generated from the households to the transfer station which is being done by members of the households themselves, Two different methods were identified to be the major types of waste collection services in the study area. The house to house services used mostly by the waste contractors in the low and medium density areas and the bring system of waste collection.

\subsubsection{House to House Services}

These types of wastes collection are only executed by the formal waste contractors with legal registration in the medium and low density areas. Sub- wards of Federal Low- cost, Tambari, Tudun Salmanu, Old GRA and New GRA (West) are the areas where the formal private waste contractors operate. Most of those contractors uses pickup vans and open trucks and side-loaders to transport the waste to disposal points (open dump) usually at the outskirts of the town. Collection is usually done manually by emptying the waste container in the trucks. Open - 
metal drum without lids and painted green were the common waste storage containers used by the waste contractors. The crew members which their number varies from 3-6, emptied the drums into side loader trucks, pick up vans or compactor trucks.

\subsubsection{The Bring-System of Waste Collection}

The bring-system in this study refers to the type of waste collection usually being used by the major waste contractors (COSMOPOLITAN) and the municipal agency (BASEPA) in Bauchi metropolis. The process involved householders to bring and dump their wastes at designated but sometimes unauthorized spaces. Observations revealed the system to be of two forms.

i) Sub - wards within the old-walled city; Wunti, Kofar Wambai, Shekal, Gwallaga, and Unguwar Gwabba which were along the dual- carriage ways dumped their waste every day at any available spaces by the road sides for collection by the municipality.

ii) Sub - wards of Federal Low- cost, Tambari, Yelwan Tudu, Old GRA, New GRA and Tudun Salmanu brings their waste to a designated transfer station or unauthorized public spaces. That is those households who received waste collection services by the municipal agency. The collection is usually forthrightly or monthly. However, respondents interviewed complained of non- or delay of the waste collection by the municipality. This threw the health of the nearby inhabitants' into risks of diseases caused by mosquitoes and rodents.

\subsubsection{Alternative Waste Disposal by the Households}

Households in the study area resolved to various available alternatives to discard their waste when not collected by the municipal agency or private contractors. This study found out that about $58 \%$ of the household's burn or their waste if it remained uncollected. This is usually the case in the sub-wards of Old GRA, new GRA, and medium density areas as Tambari. Observation revealed that, it's easy for the households to burn the waste because of the availability of spaces as setbacks yards and lawns in their compounds accorded to them by the architecture and planning of their areas. $34 \%$ mostly in the high density sub-wards within the old city who enjoyed the daily collection service of BASEPA/cosmopolitan cleaners claimed that they throw their waste by the road sides as was required them to do by the municipal authority.

These findings can be seen to be a common practice in Bauchi metropolis, as reported by (Ogwuche and Yusuf, 2013) where waste are dumped or burnt in open spaces. The information that can be communicated here is that householders in GRA and New GRA burn their waste despite having access to formal waste collection services. This indicates that the frequency and method of the collection may not be satisfactory to the householders within the above mentioned areas. While other households in high density sub-wards resolved to indiscriminate disposal (Open dump) when not confronted with adequate waste collection services. The implication here is that inadequate and unreliable waste collection services, as provided by the formal service provider's lack of enforcement of regulations from the side of municipal agency (BASEPA) and lack of accessibility to collection and disposal facilities by the households prompted and encourages the persistence of these practices in Bauchi metropolis. This argument is in line with Anand (1999) as reported by Solomon (2011), that when primary waste collection services are not reliable, the inceptive is to explore other options and when regulations is either absent or the majority are non-compliant the incentive is to dump waste in open access spaces such as streets and public spaces.

\subsection{CONCLUSION AND RECOMMENDATION}

Bauchi metropolis, the capital of Bauchi state Nigeria, is a town comprising of different categories of social class of families living in the old city (surrounded by the town wall-Ganuwa), the GRA's and sub-urban areas. These families (households) generate waste as a result of various domestic social and economic activities that affects both volume and composition. Once generated, the wastes have to be stored somehow and somewhere until the moment the wastes can be handed over to a third party that will take care of the wastes. When wastes are not properly disposed of and timely removed from the living environment of the households a lot of negative consequences are shown to result to health associated risks, bad odours, degradation of eco-and water systems are all among the unwanted negative side effects of ill functioning waste management system. Mismatch, malfunctioning and mismanagement can be said to be term appropriately referred to the everyday reality of waste management in Bauchi. Poor institutional performance absence of adequate waste management services, domestic actors resort to various kinds of handling practice that are harmful to the environment such as burning of waste when not collected, illicit and indiscriminate disposals in drains and road sides are all examples of practices that lack of regulation and enforcement would favoured. 
This study documented disparities that exist between the actual waste management practices of the household and municipal waste management service delivery and requirements on the other hand. This mismatch between the rationality of municipal authorities on the one hand and social and life world rationalities of householders on the other should be understood by relevant stakeholders in urban waste management. Therefore the important contribution of this research is that, in order to effectively improve solid waste management at both the municipal and the local level of households, the specific nature and dynamic of household practices have to be considered and taken into account when designing new interventions, both socially, economically and technically. A further research on the dynamics of the "waste- junction" or transfer stations, where the down and upstream actors met on the waste management chain is the key to sustainability.

\subsection{REFERENCES}

Abdelgawad A.M. (2015). Assessment of Municipal Solid Waste System in Asyut Governorate, Egypt. Proceedings Sardinia 2015, Fifteenth International Waste Management and Landfill Symposium. S. Margherita di Pula, Cagliari, Italy; 5 - 9 October 2015. CISA Publishers Italy.

BASEPA (2017). Bauchi State Environmental Protection Agency: Waste Management Strategy Report for 2017. A Publication of Bauchi State Environmental Protection Agency, Bauchi - Nigeria.

Bogoro, A.G. (2012). The Role of Women in Household Solid Waste Management in Bauchi Metropolitan Area. Bauchi: Unpublished Ph.D, Abubakar Tafawa Balewa University, Bauchi.

Cherian, J. and Jacob, J (2012). Management models of municipal solid waste; A review focusing on socio economic factors. International Journal of Economics and Finance. Vol.4, No 10. 2012. Pp131-139.

Cointreau-Levine, S. (1994). Private Sector Participation in Municipal Solid Waste Services in Developing Countries Volume 1. The Formal Sector UNDP/UNCHS/World Bank Urban Management Programme. The World Bank, Washington, D.C.

Karak T, Bhagat R. M. \& Bhattacharyya P. (2012). Municipal Solid Waste Generation, Composition, and Management: The World Scenario. Critical Reviews in Environmental Science and Technology, 42:15, 1509-1630 Taylor \& Francis Group, LLC ISSN: 1064-3389 print / 1547-6537 online

Maskey B \& Singh M. (2017). Household Waste Generating Factors and Composition Study for Effective Management in Gorkha Municipality of Nepal. Journal of Sustainable Development; Vol. 10, No. 6; 2017 Pp; 169-185, ISSN 1913-9063 E-ISSN 1913-9071 Canadian Center of Science and Education.

Mugagga, F. (2006). Public Private Sector Approach to Municipal Solid Waste Management. How does it work in Makindye Division, Kampala District Ugand? Trondheim, Norway: Trondheim, Norway, Norwegian University of Science and Technology (NTNU).

Ndum, A.E. (2013). Bottom-up Approach to Sustainable Solid Waste Management in African Countries: The Case of Cottbus. Unpublished Ph.D Thesis, Buea-Cameroon, Brandenburg University of Technology.

Ogwuche, J. and Yusuf, F.A. (2013). Spatial Location of Solid Waste dump sites and Collection Scheduling using GIS in Bauchi Metropolis Nigeria. European Journal of Scientific Research, 9(11) ISSN:1857-7831(print) 374-382.

Okot-Okumu, J. (2012). Solid Waste Management in African Cities - East Africa.Licensee InTech. Creative Commons Attribution License. Chp 1, Pp 3 - 20Retrieved on 12/02/2020 from http://creativecommons.org/licenses/by/3.0

Patel. N.K and Baredar P. (2016). International Journal for Innovative Research in Science \& Technology, Vol. 3, Issue 02, July 2016. Pp 253-264 ISSN (Online): 2349-6010

Peter Schubeler (1996). Conceptual Framework for Municipal Solid Waste Management in Low Income Countries. SKAT/UNDP/UNCHS (Habitat)/ World Bank/ SDC Collaborative Programme on Municipal Solid Waste Management in Low Income Countries.

Schubeler, P. Wehrle, K and Christen J. (1996). Conceptual Framework for Municipal Solid Waste Management in Low Income Countries. SKAT/UNDP/UNCHS (Habitat) World Bank/SDC. Collaborative Programme on Municipal Solid Waste Management in Low Income Countries.

Thaiyalnayaki D, Jayanthi R. (2016). Characterization and Composition of Municipal Solid Waste - A Case Study. International Journal of Civil Engineering and Technology (IJCIET.) Vol. 7, Issue 6, November-December 2016, pp. 61-66, ISSN Print: 0976-6308 and ISSN Online: 0976-6316

UNDP, (1996). Conceptual Framework for Municipal Solid Waste Management in Low-Income Countries. A Publication of United Nation Development Programme, New York - USA.

Usman, H.A. (2017). Framework for Sustainable Households Solid Waste Management for Bauchi Metropolis, Unpublished Ph.D Thesis, Abubakar Tafawa Balewa University; Bauchi. 